\title{
The Effects of an Obesogenic Diet on Liver Oxysterol Metabolism in C57BL/6J Mice
}

\author{
JOSHUA S. WOOTEN, HUAIZHU WU, JOE RAYA, AMIR MANSOORI, XIAO-YUAN, \\ DAI PERRARD, JERRY PERRARD, AND RON C. HOOGEVEEN
}

Baylor College of Medicine, Department of Medicine, Section of Atherosclerosis and Vascular Medicine, Houston, TX 77030

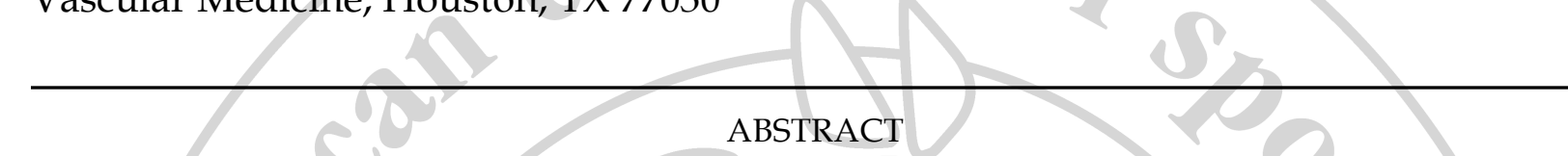

Oxysterols are key regulators of lipid metabolism and play a role in the etiology of atherosclerosis; however, our current understanding of tissue levels of oxysterols during different disease states such as obesity is limited. The purpose of this study was to quantify the effects of obesity induced by a high fatcholesterol (HFC) diet on liver oxysterol metabolism. Male C57BL/6J mice were fed either a standard control diet $(5.0 \% \mathrm{w} / \mathrm{w}$ fat, $0.03 \% \mathrm{w} / \mathrm{w} \mathrm{chol})$ or a HFC $(21.0 \% \mathrm{w} / \mathrm{w}$ fat, $0.15 \% \mathrm{w} / \mathrm{w}$ chol $)$ diet for 24 weeks. Comparisons between dietary groups were made with independent sample $t$-tests. Total body mass and liver tissue mass of the HFC group was greater (33.2 $\pm 5.2 \mathrm{vs} .49 .0 \pm 3.6 \mathrm{~g}$ and $1.4 \pm 0.3 \mathrm{vs} .3 .9 \pm 0.8 \mathrm{~g}$, respectively; $P<0.05)$ than the control group. In the HFC group, a 3.3 fold increase in lipid mass of the liver tissue was due to increased levels of cholesterol $(0.10 \pm 0.01$ vs. $0.33 \pm 0.06 \mathrm{mg} / \mathrm{mg}$ protein; $P<0.05)$ and triglyceride $(0.37 \pm 0.05$ vs. $1.49 \pm 0.12 \mathrm{mg} / \mathrm{mg}$ protein; $P<0.05)$. In the HFC diet, $4 \beta-O H, 5,6 \beta$-epoxy, and $27-$ $\mathrm{OH}$ were greater and 7-keto was lower when compared to the control diet. Post-dietary liver $4 \beta$-OH, 5,6 3 epoxy, and 27-OH were increased in the HFC diet group. Interestingly, despite increased oxysterol levels no significant changes in mRNA levels were observed for oxysterol-related enzymes CYP3A11, CYP27A1 or CYP7A1. The 24-week HFC diet was effective at promoting obesity and hepatic steatosis in mice. Due to the low concentration of oxysterols in the diet, it is unlikely that the oxysterols in the diet had a significant impact on liver oxysterols. Furthermore, our results suggest that the increased hepatic oxysterol levels observed in mice on the obesogenic diet were not due to increased rates of oxysterol synthesis.

\begin{tabular}{|l|l|l|l|l|}
\hline Variables & $\begin{array}{l}\text { Control Diet (ng/mg } \\
\text { of chow) }\end{array}$ & $\begin{array}{l}\text { HFC Diet (ng/mg of } \\
\text { chow) }\end{array}$ & $\begin{array}{l}\text { Control Liver (ng/mg } \\
\text { of protein) }\end{array}$ & $\begin{array}{l}\text { HFC Liver (ng/mg of } \\
\text { protein) }\end{array}$ \\
\hline $4 \beta$-hydroxycholesterol & $0.5 \pm 0.03$ & $0.7 \pm 0.1^{*}$ & $222.5 \pm 36.9$ & $595.0 \pm 153.4^{*}$ \\
\hline $5,6 \beta$-epoxycholesterol & $1.8 \pm 0.2$ & $3.7 \pm 0.9^{*}$ & $23.7 \pm 6.7$ & $44.1 \pm 14.4^{*}$ \\
\hline $5,6 \alpha$-epoxycholesterol & $1.7 \pm 0.3$ & $3.0 \pm 0.9$ & $30.6 \pm 7.9$ & $22.8 \pm 4.0$ \\
\hline $7-$-ketocholesterol & $4.2 \pm 0.2$ & $3.6 \pm 0.4^{*}$ & $30.6 \pm 6.4$ & $29.7 \pm 12.0$ \\
\hline $7 \alpha$-hydroxycholesterol & $3.2 \pm 2.4$ & $4.7 \pm 0.6$ & $18.2 \pm 3.1$ & $19.8 \pm 4.0$ \\
\hline $7 \beta$-hydroxycholesterol & $5.5 \pm 0.3$ & $5.8 \pm 0.8$ & $33.4 \pm 8.2$ & $41.5 \pm 8.6$ \\
\hline 27-hydroxycholesterol & $0.1 \pm 0.04$ & $9.7 \pm 1.0^{*}$ & $19.2 \pm 7.2$ & $34.7 \pm 5.4^{*}$ \\
\hline Note. (n=5 per group). Mean \pm SD. ${ }^{*}$ Control vs. HFC, $P<0.05$. & & & \\
\hline
\end{tabular}

